all-round men possessing all the qualities which are necessary for success in the Colonies.

The immediate problem to be solved is how to prevent a period of overseas service, causing as it does a serious break in the home career, from injuring the future prospects of a technical man. Obviously no general solution is possible : the first practicable step suggested by the Old Centralians is to form an Overseas Engineers Association, which would enjoy the active support of all home professional bodies representative of engineers and engineering colleges as well as of old students' associations, consulting engineers, contracting firms and large engineering and industrial firms. Such an organization would keep a record of engineers qualified to carry out work abroad. It would constitute a source from which contributing organizations would draw engineering staff when need arose and make it easier for the employers to obtain fully trained and qualified men.

The problem is to some extent associated with the training of the engineer, and the time may be opportune to re-examine the engineering courses in relation to modern requirements. The young American engineer, for example, is more highly favoured on outdoor work by overseas employers; it may be that his training, though less theoretical, none the less fits him better for his work. Mining engineering is known to have this aspect of its teaching under consideration.

It is widely held that the present three-year undergraduate course in engineering in British universities and technical colleges should be extended to four years, not so much with a more extensive curriculum, but designed rather that the students should be given more time to think over their work and to read for themselves.

Looking at the question broadly, it would appear to have two aspects : one is that of giving Englishmen a chance to go abroad without injuring their prospects on their return, which is largely a question of organization and is possible of solution on lines such as the Old Centralians visualize. The more important aspect, however, is the technical equipment of the Englishman so as to enable him to hold his own in a competitive nationalistic world. Besides personality and character and professional knowledge, he must have ideas and originality. These can be trained out of a student more easily than developed in him.

\title{
The Trend of Population in Great Britain
}

$T$ HE debate on this subject which took place in the House of Commons on February 10 is one of the many signs of the increasing interest which is being felt in Great Britain in population questions. Mr. J. R. H. Cartland, who moved the resolution, expressed the view, which was accepted by the House, that "the tendency of the population to decline may well constitute a danger to the maintenance of the British Empire and to the economic well-being of the nation"; and the Government was requested to institute an inquiry into the problem. No new facts were brought forward during the debate, which proceeded on what may be called orthodox lines. Attention was directed to the gradual diminution of the birth-rate since 1875 ; to the resulting fall in the net reproduction rate; and to the ageing of our population. The question of birth-control was touched upon, and also the present general tendency of married couples to have small families. Mr. Cartland mentioned the existence of the unofficial Population Investigation Committee, which has been formed at the instance of the Eugenics Society.

Mr. Cartland quoted the important pronouncement of the Chancellor of the Exchequer when he introduced the budget on April 15, 1935: "I must say that I look upon the continued diminution of the birth-rate in this country with considerable apprehension. At the present time it may seem that we have here a larger population than we are-able to support in England. . . . But I have a feeling that the time may not be far distant ... when the countries of the British Empire will be crying out for more citizens of the right breed and when we in this country shall not be able to supply the demand."

Mr. D. Sandys, who seconded the motion, directed attention to the rapid increase in the populations of Russia and Japan. He recalled the estimate of Dr. Enid Charles to the effect that, in sixty years' time, 64 per cent of the women in Great Britain may be past the child-bearing age. He indicated the possibility that, for want of British 
emigrants, the Dominions might eventually "be forced to seek emigrants from Asiatic and Eastern European countries". $\mathrm{He}$ is of opinion that a declining and ageing population is particularly vulnerable to attack.

These and other contributions to the debate are, no doubt, ultimately based upon the important calculations of Dr. Kuczynski, who has shown how to compute the net reproduction rate of a population by a consideration of the number of future mothers that, say, a thousand mothers will give birth to. To use the words of Prof. A. M. CarrSaunders, in his book "World Population" (1936), "This simple and beautiful method which we owe to Mr. Kuczynski gives precisely what we need. He has applied it so far as the data are available. But in order to calculate the net reproduction rate we require data concerning specific fertility as well as specific mortality. . . They are not available for England and Wales because the age of the mother is not recorded on the birth certificate." Here, then, is a simple step towards the calculation of accurate rates, which the Government can take at once, namely, to direct that, in future, the age of the mother shall be entered on the birth certificate.

One or two of those who took part in the debate stressed the desirability of paying attention to the quality of our population.

With regard to the unofficial Population Investigation Committee, alluded to above, this Committee, of which the chairman is Prof. CarrSaunders, has been formed to examine the factors influencing contemporary trends of population in England and Wales, with special reference to the fall of the birth-rate. It is common ground that, unless a change - at present unforeseen-occurs in social conditions, it is probable that, after some fifteen years or so, the population of Great Britain will begin to decline somewhat rapidly. The objects of the Committee are to ascertain what are the causes of this state of things ; to determine, so far as possible, the social effects of such a rapid decline; and to see how a catastrophic decline can be avoided. It has been stated on behalf of the Committee that it does not at present take part in propaganda designed to modify existing population trends.

It is to be noted that Mr. R. S. Hudson, speaking for the Government, said: "We do not propose to set an enquiry on foot, because the subject is continuously under enquiry in my Department [the Ministry of Health]. We shall welcome any assistance, but we think it is essentially a matter for the Government and not for outside societies." It may be presumed that the reports of the Population Investigation Committee will be studied and made use of by Mr. Hudson's department.

Mr. Hudson did not agree with those who hold extreme views about the population position. He said that statisticians are not infallible, and that they are not infrequently wrong in their forecasts. They are, of course, limited by the information available and they are obliged to accept existing data. They have not, alas! the gift of prophecy. Our social structure is of great intricacy, and the fall in the birth-rate may be due to many causes. One such cause may, perhaps, be a perfectly wholesome revulsion from the largely unsatisfactory conditions of the huge Victorian families of a generation or two ago. Few of those who have had the personal experience of membership of a very large family would desire their children to go through the same experience. The argument is not all on one side. There are some who think that a decline in our numbers of a few millions, if the decline could then be arrested, might not be altogether such a bad thing. From a defence point of view there would be less food to import if the country is beleaguered; we might strike a better balance between our consumption and our home production of food, if there were fewer of us ; we might restore some of the lost amenities of our countryside; and the better spacing of the children might improve their quality.

It is not impossible that, as a result of the relief afforded by a reduction of our numbers, the population might tend to increase again. In the future-thirty-three years from now-if our numbers in Great Britain were to have come down by some five or six millions, from their present figure of 45.5 millions, as has been predicted, that would bring us to about the same numbers that we had in 1906. Some students of the problem would not object to such a diminution, provided always, as the lawyers say, that the diminution did not continue indefinitely, and that a stationary condition could shortly be reached. But there is no certainty about the matter, and at the best we can only make reasoned guesses. So we may hope that the Government, the Population Investigation Committee and other bodies concerned, may continue their useful labours, moved by a single desire to predict with reasonable probability the situations which may arise in the future. 